\title{
A 4 year follow-up study of cognitive functioning in patients with type 2 diabetes mellitus
}

\author{
E. van den Berg • Y. D. Reijmer • J. de Bresser • \\ R. P. C. Kessels • L. J. Kappelle • G. J. Biessels • \\ on behalf of the Utrecht Diabetic Encephalopathy Study \\ Group
}

Received: 22 July 2009 /Accepted: 23 September 2009/Published online: 31 October 2009

(C) The Author(s) 2009. This article is published with open access at Springerlink.com

\begin{abstract}
Aims/hypothesis Type 2 diabetes mellitus is associated with moderate decrements in cognitive functioning, mainly in verbal memory, information-processing speed and executive functions. How this cognitive profile evolves over time is uncertain. The present study aims to provide detailed information on the evolution of cognitive decrements in type 2 diabetes over time.

Methods Sixty-eight patients with type 2 diabetes and 38 controls matched for age, sex and estimated IQ performed an elaborate neuropsychological examination in 2002-2004 and again in 2006-2008, including 11 tasks covering five cognitive domains. Vascular and metabolic determinants were recorded. Data were analysed with repeated measures
\end{abstract}

E. van den Berg $(\bowtie) \cdot$ Y. D. Reijmer · J. de Bresser •

L. J. Kappelle $\cdot$ G. J. Biessels

Department of Neurology (G03.228),

Rudolf Magnus Institute of Neuroscience,

University Medical Center Utrecht,

P.O. Box 85500, 3508 GA Utrecht, the Netherlands

e-mail: e.vandenberg-6@umcutrecht.nl

J. de Bresser

Image Sciences Institute, University Medical Center Utrecht,

Utrecht, the Netherlands

R. P. C. Kessels

Donders Institute for Brain, Cognition and Behaviour,

Radboud University Nijmegen,

Nijmegen, the Netherlands

R. P. C. Kessels

Departments of Medical Psychology and Geriatrics,

Radboud University Nijmegen Medical Centre,

Nijmegen, the Netherlands

R. P. C. Kessels

Department of Experimental Psychology, Helmholtz Instituut,

Utrecht University,

Utrecht, the Netherlands analysis of variance, including main effects for group, time and the group $\times$ time interaction.

Results Patients with type 2 diabetes showed moderate decrements in information-processing speed (mean difference in $z$ scores $[95 \% \mathrm{CI}]-0.37[-0.69,-0.05])$ and attention and executive functions $(-0.25[-0.49,-0.01])$ compared with controls at both the baseline and the 4 year follow-up examination. After 4 years both groups showed a decline in abstract reasoning $(-0.16[-0.30,-0.02])$ and attention and executive functioning $(-0.29[-0.40,-0.17])$, but there was no evidence for accelerated cognitive decline in the patients with type 2 diabetes as compared with controls (all $p>0.05$ ).

Conclusions/interpretation In non-demented patients with type 2 diabetes, cognitive decrements are moderate in size and cognitive decline over 4 years is largely within the range of what can be viewed in normal ageing. Apparently, diabetes-related cognitive changes develop slowly over a prolonged period of time.

Keywords Cognitive decline $\cdot$ Dementia $\cdot$ Diabetes mellitus · Longitudinal

$\begin{array}{ll}\text { Abbreviations } \\ \text { BDI-II } & \begin{array}{l}\text { Beck Depression Inventory, 2nd edition } \\ \text { TICS-m }\end{array} \\ & \begin{array}{l}\text { Modified Telephone Interview for Cognitive } \\ \text { Status }\end{array} \\ \text { WAIS-III } & \text { Wechsler Adult Intelligence Scale, 3rd edition }\end{array}$

\section{Introduction}

The global prevalence of diabetes is expected to rise from 171 million persons in 2000 to 366 million in 2030 [1]. Prevalence estimates for dementia rise from 24 million in 
2001 to 84 million in 2040 [2]. There is compelling evidence for a link between diabetes and dementia, particularly in persons over 65 years of age. Longitudinal studies report a 1.5- to twofold increased risk of dementia, both Alzheimer's disease or vascular dementia, in individuals with diabetes compared with those without [3].

Numerous cross-sectional studies have reported on neuropsychological functioning in non-demented patients with type 2 diabetes mellitus (e.g. [4, 5]). Systematic reviews of the literature report a cognitive profile of mild to moderate decrements in cognitive functioning in patients with type 2 diabetes $[6,7]$. These decrements are most consistently found in information-processing speed, verbal memory and executive functioning [6, 7], possibly reflecting a diminished ability to efficiently process unstructured information [8]. It is, however, less clear how these cognitive decrements evolve over time. Several longitudinal population-based studies have examined the risk of cognitive decline associated with type 2 diabetes in individuals who were not demented at baseline, but these studies have generally included only a limited number of psychometric tests or applied cognitive screening instruments, such as the Mini Mental State Examination, that may be criticised for lack of sensitivity $[9,10]$. The present study provides detailed assessment of the evolution of cognitive decrements in patients with type 2 diabetes over a 4 year period, relative to control participants, using an elaborate neuropsychological examination. We hypothesised that type 2 diabetes is associated with accelerated cognitive decline.

\section{Methods}

Participants The baseline examination (2002-2004) included 122 patients with type 2 diabetes and 56 control participants aged between 56 and 80 years, matched on age, sex and estimated IQ [8, 11]. Patients were recruited through general practitioners in the region. Control participants were recruited among the spouses or acquaintances of the patients. For inclusion the patients had to have had type 2 diabetes for at least 1 year, be functionally independent and Dutch speaking. Exclusion criteria for all participants were a psychiatric or neurological disorder (unrelated to diabetes) that could influence cognitive functioning and a history of alcohol or substance abuse or dementia. Control participants with a fasting blood glucose $\geq 7.0 \mathrm{mmol} / 1$ were also excluded. At follow-up 4 years later, seven participants had died, four could not be contacted and 59 were not willing or able to participate. Reasons for not participating were: lack of interest $(n=28)$; comorbidity $(n=22$; three reported dementia [two patients, one control]); and other reasons $(n=9)$. The remaining 108 participants were re-examined between 2006 and 2008 (mean follow-up time
$4.1 \pm 0.4$ years). One patient with type 2 diabetes was excluded because of severe comorbid disease and one control participant fulfilled the criteria for type 2 diabetes and was therefore excluded from the control group, leaving 106 participants (68 patients and 38 control participants) in the present analysis.

The non-participants $(n=70)$ did not differ from the participants $(n=106)$ with regard to baseline age, sex or estimated premorbid IQ (all $p>0.05$ ). To control for possible selective loss at follow-up we examined the cognitive status of both non-participants and participants ( \pm 1 week after their participation in the follow-up examination) with the Dutch version of the Telephone Interview for Cognitive Status [12], a 12 item screening instrument designed to identify persons with dementia [13]. The Interview was slightly modified (TICS-m) by including a delayed word-list recall which resulted in a maximum score of 50 [14]. The TICS-m was obtained from 43 of the 70 non-participants (i.e. $73 \%$ of the 59 non-participants who were still alive and could be contacted) and 99 of the 106 participants (93\%). TICS-m scores were normally distributed across the whole study sample. The TICS-m performance for the non-participants was similar to the participants (non-participants mean score $35.4 \pm 5.2$, participants $36.5 \pm 4.6, F[1,140]=1.67, p=0.20)$. Only three patients with type 2 diabetes (two non-participants, one participant) and two control participants (one nonparticipant, one participant) performed below the cut-off score of $28\left(\chi^{2}[1]=0.24, p=0.62\right)$, which is indicative for cognitive impairment [15]. Hence, among the nonparticipants four patients with type 2 diabetes (3\% of baseline sample) and two controls (4\% of baseline sample) had cognitive impairment based on self-reported dementia or a low TICS-m score $\left(\chi^{2}[1]=0.10, p=0.76\right)$. The study was approved by the medical ethics committee of the University Medical Center Utrecht, Utrecht, the Netherlands. Written informed consent was obtained from all participants.

Neuropsychological assessment At follow-up all participants performed an extensive neuropsychological assessment, identical to the baseline examination [8]. Parallel versions were used for memory tests to control for possible material-specific learning effects [16]. The neuropsychological assessment consisted of 11 verbal and non-verbal tasks, administered in a fixed order that took about $90 \mathrm{~min}$ to complete. The tasks were divided into five cognitive domains to reduce the amount of neuropsychological variables in the analysis and for clinical clarity [8]. This division was made a priori, according to standard neuropsychological practice and cognitive theory, as described in detail in Lezak et al. [16]. The domain 'abstract reasoning' was assessed by Raven Advanced Progressive Matrices (12 item short form). The domain 'memory' included four 
Table 1 Baseline characteristics of the patients with type 2 diabetes and the control group

\begin{tabular}{|c|c|c|c|c|c|c|}
\hline \multirow[t]{2}{*}{ Characteristic } & \multicolumn{3}{|l|}{ Baseline } & \multicolumn{3}{|l|}{ Follow-up } \\
\hline & Type 2 diabetes & Control group & $p$ value & Type 2 diabetes & Control group & $p$ value \\
\hline$n$ & 68 & 38 & - & 68 & 38 & - \\
\hline Age (years) & $65.6 \pm 5.6$ & $64.8 \pm 4.8$ & 0.44 & $69.8 \pm 5.6$ & $68.9 \pm 4.8$ & 0.44 \\
\hline Male sex $(n)$ & $32(47 \%)$ & $19(50 \%)$ & 0.77 & - & - & - \\
\hline Educational level (median (IQR)) & $4(3-5)$ & $4(4-5)$ & 0.87 & - & - & - \\
\hline Estimated IQ (points) & $100 \pm 16$ & $103 \pm 13$ & 0.39 & $97 \pm 15$ & $98 \pm 15$ & 0.64 \\
\hline Diabetes duration (years) & $9.1 \pm 6.3$ & - & - & - & - & - \\
\hline $\mathrm{HbA}_{1 \mathrm{c}}(\%)$ & $6.9 \pm 1.1$ & $5.5 \pm 0.3$ & $<0.001$ & $7.2 \pm 1.0$ & $5.7 \pm 0.4$ & $<0.001$ \\
\hline Hypertension $^{\mathrm{a}}$ & $49(72 \%)$ & $11(29 \%)$ & $<0.001$ & $53(78 \%)$ & $19(50 \%)$ & $<0.01$ \\
\hline BMI $\left(\mathrm{kg} / \mathrm{m}^{2}\right)$ & $27.9 \pm 4.0$ & $26.7 \pm 5.2$ & 0.19 & $28.4 \pm 4.8$ & $26.7 \pm 4.5$ & 0.09 \\
\hline Total cholesterol $(\mathrm{mmol} / \mathrm{l})$ & $5.0 \pm 0.9$ & $5.9 \pm 1.2$ & $<0.001$ & $4.5 \pm 1.0$ & $5.9 \pm 1.0$ & $<0.001$ \\
\hline History of stroke & $3(4 \%)$ & $1(3 \%)$ & 0.65 & $3(4 \%)$ & $1(3 \%)$ & 0.65 \\
\hline Any macrovascular event $\mathrm{t}^{\mathrm{b}}$ & $18(27 \%)$ & $2(5 \%)$ & 0.007 & $20(29 \%)$ & $3(8 \%)$ & 0.01 \\
\hline Beck Depression Inventory & $7.2 \pm 5.0$ & $4.4 \pm 3.5$ & 0.005 & $8.5 \pm 7.0$ & $5.5 \pm 5.1$ & 0.03 \\
\hline Beck Depression Inventory $>13$ & $5(9 \%)$ & $0(0 \%)$ & 0.07 & $9(16 \%)$ & $1(3 \%)$ & 0.04 \\
\hline
\end{tabular}

Data are presented as mean $\pm \mathrm{SD}$ or $n(\%)$ unless otherwise specified

${ }^{a}$ Defined as systolic blood pressure $>160 \mathrm{mmHg}$, diastolic blood pressure $>95 \mathrm{mmHg}$ or use of blood-pressure-lowering medication

${ }^{b}$ Defined as a history of myocardial infarction, stroke, or surgery or endovascular treatment for coronary, carotid of peripheral (legs, abdominal aorta) artery disease

$p$ values derived using univariate analysis of variance

$\mathrm{IQR}$, interquartile range

subdomains: 'working memory' assessed by the forward and backward digit span of the Wechsler Adult Intelligence Scale, 3rd edition (WAIS-III) and the Corsi Block-tapping Task (the product scores of the span length $\times$ the number of correctly recalled sequences were recorded [17]); 'immediate memory and learning rate', including verbal memory assessed by the Rey Auditory Verbal Learning Test and visual memory assessed by the Location Learning Test; 'forgetting rate' assessed by the delayed task of the Rey Auditory Verbal Learning Test and the Location Learning Test; and 'incidental memory' assessed by the delayed trial of the modified Taylor Complex Figure. The domain 'information-processing speed' was assessed by the Trailmaking Test-Part A, the Stroop Color-Word Test (Parts I and II), and the subtest Digit Symbol of the WAIS-III. The domain 'attention and executive function' was assessed by the Trail-making Test-Part B (ratio score), the Stroop Color-Word Test (Part III; ratio score), the Brixton Spatial Anticipation Test, a letter fluency test using the ' $N$ ' and 'A', and category fluency (animal naming). The domain 'visuoconstruction' was assessed by the copy trial of the modified Taylor Complex Figure.

To compare the five different cognitive domains between the two groups the raw test scores were standardised into $z$ scores per cognitive domain. These $z$ scores were calculated by using the pooled mean of baseline scores of the whole study sample. The $z$ score for each domain was derived by calculating the mean of the $z$ scores for tests comprising that domain. Depressive symptoms were assessed with the Dutch version of the Beck Depression Inventory, 2nd edition (BDI-II [18]). The total score on this self-rated depressive symptoms inventory and the proportion of persons scoring $>13$ were recorded [19].

Medical history and biometric measurements Procedures at baseline and follow-up were identical [8]. Medical history was assessed with a standardised questionnaire addressing diabetes duration, medication use, history of cardiovascular disease (including stroke), smoking and alcohol consumption. Fasting glucose, $\mathrm{HbA}_{1 \mathrm{c}}$ and cholesterol levels were measured with standard laboratory testing. Blood pressure was measured in a seated position at three time-points during the half-day visit (Omron MX3; Omron, Mannheim, Germany). Hypertension was defined as a systolic blood pressure $>160 \mathrm{mmHg}$, a diastolic blood pressure $>95 \mathrm{mmHg}$ or self-reported use of blood-pressure-lowering medication. 'Any macrovascular event' was defined as a history of myocardial infarction, stroke, or surgery or endovascular treatment for coronary, carotid or peripheral (legs, abdominal aorta) artery disease. Retinopathy was defined as a score of $\geq 1.5$ on the Wisconsin Epidemiologic Study of Diabetic Retinopathy scale [20]. Neuropathy was defined as 
Table 2 Raw test scores of the patients with type 2 diabetes and the control group at the baseline and follow-up examination
Data are mean $\pm \mathrm{SD}$

${ }^{a}$ Higher test scores reflect worse performance

Raven APM, Raven Advanced Progressive Matrices; RALVT, Rey Auditory Verbal Learning Test; LLT, Location Learning Test; TMT, Trail-making Test

\begin{tabular}{|c|c|c|c|c|}
\hline \multirow[t]{2}{*}{ Test } & \multicolumn{2}{|c|}{ Type 2 diabetes $(n=68)$} & \multicolumn{2}{|c|}{ Control group $(n=38)$} \\
\hline & Baseline & Follow-up & Baseline & Follow-up \\
\hline Raven APM (short form) & $6.3 \pm 2.9$ & $6.3 \pm 2.9$ & $7.3 \pm 2.1$ & $6.5 \pm 2.4$ \\
\hline \multicolumn{5}{|l|}{ WAIS-III Digit Span } \\
\hline Forward (product score) & $45.1 \pm 20.5$ & $41.0 \pm 20.0$ & $47.6 \pm 19.1$ & $48.6 \pm 20.6$ \\
\hline Backward (product score) & $23.1 \pm 15.7$ & $21.0 \pm 15.0$ & $32.5 \pm 23.0$ & $27.5 \pm 22.0$ \\
\hline \multicolumn{5}{|l|}{ Corsi Block-tapping Test } \\
\hline Forward (product score) & $38.0 \pm 13.8$ & $36.5 \pm 11.7$ & $37.8 \pm 9.5$ & $37.2 \pm 11.3$ \\
\hline Backward (product score) & $37.1 \pm 13.8$ & $37.4 \pm 13.6$ & $41.3 \pm 12.8$ & $38.8 \pm 13.2$ \\
\hline \multicolumn{5}{|l|}{ Rey Auditory Verbal Learning Test } \\
\hline Total trials $1-5$ & $39.2 \pm 9.0$ & $38.4 \pm 10.8$ & $43.1 \pm 11.4$ & $43.4 \pm 10.8$ \\
\hline Delayed recall & $7.6 \pm 2.7$ & $7.7 \pm 2.8$ & $8.7 \pm 2.8$ & $9.2 \pm 3.1$ \\
\hline Recognition & $28.2 \pm 1.9$ & $28.5 \pm 1.7$ & $29.1 \pm 1.4$ & $29.0 \pm 1.5$ \\
\hline \multicolumn{5}{|l|}{ Location Learning Test } \\
\hline Total trials $1-5^{\mathrm{a}}$ & $24.9 \pm 21.0$ & $23.7 \pm 22.1$ & $24.8 \pm 19.9$ & $20.5 \pm 17.1$ \\
\hline Learning index & $0.59 \pm 0.28$ & $0.54 \pm 0.31$ & $0.66 \pm 0.28$ & $0.61 \pm 0.29$ \\
\hline Delayed trial $^{\mathrm{a}}$ & $2.0 \pm 3.3$ & $2.5 \pm 3.5$ & $1.7 \pm 2.9$ & $1.7 \pm 2.8$ \\
\hline \multicolumn{5}{|l|}{ Complex Figure Test } \\
\hline Copy & $32.4 \pm 3.9$ & $33.7 \pm 2.7$ & $33.0 \pm 3.3$ & $33.1 \pm 3.0$ \\
\hline Delay & $17.4 \pm 6.6$ & $17.8 \pm 6.1$ & $19.9 \pm 4.5$ & $18.4 \pm 5.2$ \\
\hline \multicolumn{5}{|l|}{ Stroop Color-Word Test } \\
\hline Part $\mathrm{I}^{\mathrm{a}}$ & $50.4 \pm 12.8$ & $51.2 \pm 9.6$ & $47.0 \pm 8.9$ & $46.1 \pm 7.6$ \\
\hline Part II ${ }^{\mathrm{a}}$ & $65.1 \pm 13.6$ & $66.6 \pm 11.6$ & $61.3 \pm 14.2$ & $62.8 \pm 13.8$ \\
\hline Part III ${ }^{\mathrm{a}}$ & $124.6 \pm 46.6$ & $135.2 \pm 46.3$ & $113.1 \pm 45.5$ & $118.6 \pm 41.5$ \\
\hline \multicolumn{5}{|l|}{ TMT } \\
\hline Part $A^{a}$ & $49.5 \pm 21.0$ & $47.1 \pm 22.9$ & $38.6 \pm 9.7$ & $38.1 \pm 12.1$ \\
\hline Part $B^{a}$ & $114.2 \pm 44.2$ & $138.0 \pm 83.8$ & $89.1 \pm 25.1$ & $97.1 \pm 30.7$ \\
\hline WAIS-III Digit Symbol & $54.9 \pm 16.8$ & $50.4 \pm 15.7$ & $56.6 \pm 12.2$ & $56.6 \pm 13.5$ \\
\hline \multicolumn{5}{|l|}{ Verbal fluency } \\
\hline Letter (mean of $\mathrm{N}+\mathrm{A}$ ) & $10.4 \pm 4.8$ & $9.7 \pm 4.2$ & $12.0 \pm 4.1$ & $11.1 \pm 4.0$ \\
\hline Category (Animals) & $33.8 \pm 10.0$ & $31.4 \pm 10.1$ & $34.1 \pm 7.7$ & $31.4 \pm 10.1$ \\
\hline Brixton Spatial Anticipation Test ${ }^{\mathrm{a}}$ & $20.8 \pm 7.3$ & $22.1 \pm 6.3$ & $18.1 \pm 6.6$ & $22.1 \pm 6.3$ \\
\hline
\end{tabular}

a score $\geq 6$ on a modified version of the Toronto Clinical Neuropathy Scoring System [21, 22].

Statistical analysis Between-group differences in characteristics were analysed with analysis of variance for continuous variables, Mann-Whitney $U$ tests for non-parametric data and $\chi^{2}$ tests for proportions. The primary outcome measures were the $z$ scores of the five cognitive domains, which were analysed with repeated-measures ANOVA, including the effect of time, group and the time $\times$ group interaction. The effect of time reflects the mean change in cognitive performance over time for the whole study sample; the effect of group reflects the mean difference between the patients with type 2 diabetes and the control group; the time $\times$ group interaction reflects the additional change over time attributable to diabetes status. $p$ values $<0.05$ were considered statistically significant.
In a secondary analysis additional adjustment for BDI-II depressive symptoms was performed to examine a possible confounding effect of depression. Moreover, within the diabetes group cognitive functioning (domains information processing speed and attention and executive functioning) was compared between patients with high or low baseline $\mathrm{HbA}_{1 \mathrm{c}}$ (dichotomised at the median level of $6.6 \mathrm{mmol} / \mathrm{l}$ ), with or without baseline hypertension and with or without 'any macrovascular event' at baseline.

\section{Results}

Table 1 shows the characteristics of the patients with type 2 diabetes and the control group at baseline. The groups were similar in age, estimated IQ and sex distribution. As expected, between-group differences in glycaemic control, 
vascular risk factors and vascular events were still present at the follow-up examination after 4 years. At baseline six (9\%) patients were treated with diet only, $42(62 \%)$ used oral glucose-lowering medication and 20 (29\%) used insulin. The baseline prevalence of retinopathy and neuropathy was $32 \%$ and $35 \%$, respectively.

Table 2 shows the raw test scores of the neuropsychological examination for both groups at baseline and follow-up. To limit the number of comparisons, only the differences in domain scores were compared statistically (Table 3). As is shown in Fig. 1 the results of the repeatedmeasures ANOVA demonstrated a significant decline in performance over 4 years for the whole sample on the domains abstract reasoning and attention and executive functions (mean change in $z$ scores $-0.16, F[1,93]=4.83$, $p=0.03$ and $-0.29, F[1,103]=25.59, p<0.001$, respectively). A significant main effect of group was found in information-processing speed (mean difference in $z$ scores for patients with type 2 diabetes compared with controls: $-0.37, F[1,102]=6.68, p<0.05)$ and attention and executive functions $(-0.25, F[1,103]=3.01, p<0.05)$, and a trend in the same direction on memory $(-0.16, F[1,103]=3.42$, $p=0.07)$. There were no significant time $\times$ group interactions, although there was a trend towards interaction for visuoconstruction $(p=0.07)$. Additional adjustment for BDI-II score or exclusion of persons with a BDI-II score $>13$ did not change the results. Visual inspection of the distribution of the individual $z$ scores for each domain did not reveal differences between the diabetes group and the control group. This indicated that it was the diabetes group as a whole that had a worse mean performance, rather than a subgroup of patients with type 2 diabetes performing in the lowest part of the $z$ score distribution.

In secondary analyses within the diabetes group no significant group differences or time $\times$ group interactions with regard to $\mathrm{HbA}_{1 \mathrm{c}}$ level were found (information-processing speed mean group difference $[95 \% \mathrm{CI}]=0.07[-0.37,0.51]$; attention and executive functions $-0.08[-0.38,0.23])$ or the presence of hypertension (information-processing speed 0.11 $[-0.38,0.60]$; attention and executive functions $0.01[-0.33$, $0.34])$. For patients with type 2 diabetes with 'any macrovascular event' there was a trend toward a worse performance on information-processing speed $(-0.46[-0.95$, $0.03]$ ), but no differences were found on attention and executive functions $(-0.19[-0.53,0.15])$.

\section{Discussion}

Patients with type 2 diabetes showed moderate decrements in cognitive functioning compared with control participants matched for age, sex and estimated IQ, both at baseline and after 4 year follow-up in the information-processing speed and attention and executive functioning domains. After 4 years a decline in abstract reasoning and attention and executive functioning was found for the whole sample, but no evidence was shown for accelerated decline in the patients with type 2 diabetes.

The profile of cognitive decrements and the size of the effects observed in the present study are comparable with the results from previous cross-sectional studies on cognition in type 2 diabetes, which show small to moderate decrements (effect sizes -0.3 to -0.6 ) particularly in the domains information-processing speed, executive functioning and memory [6]. Interestingly, the effect sizes of crosssectional studies in patients with different stages of type 2 diabetes or even prediabetic stages are remarkably similar, generally ranging from -0.3 to -0.6 [4, 23-25], indicating that these decrements may develop in the early stage of the disease and progress only gradually thereafter. Our findings on the domain visuoconstruction were dissimilar to the other domains, as the performance of the patients with type 2 diabetes tended to improve. We have no certain explanation for this observation, but the fact that this

Table 3 Differences in cognitive domain scores for patients with type 2 diabetes and the control group at the baseline and follow-up examination

\begin{tabular}{llll}
\hline Domains & $\begin{array}{l}\text { Mean change } \\
\text { over time }^{\mathrm{a}}\end{array}$ & $\begin{array}{l}\text { Mean difference between } \\
\text { T2DM and control group }\end{array}$ & $\begin{array}{l}\text { Time } \times \text { group interaction } \\
p \text { value }\end{array}$ \\
\hline Abstract reasoning & $-0.16(-0.30$ to -0.02$)$ & $-0.17(-0.57$ to 0.22$)$ & 0.20 \\
Memory & $-0.06(-0.14$ to 0.02$)$ & $-0.16(-0.34$ to 0.01$)$ & 0.15 \\
Information-processing speed & $-0.05(-0.14$ to 0.04$)$ & $-0.37(-0.69$ to -0.05$)$ & 0.23 \\
Attention and executive functions & $-0.29(-0.40$ to -0.17$)$ & $-0.25(-0.49$ to -0.01$)$ & 0.37 \\
Visuoconstruction & $0.16(-0.06$ to 0.38$)$ & $-0.06(-0.36$ to 0.24$)$ & 0.07 \\
\hline
\end{tabular}

Data are $z$ scores $(95 \% \mathrm{CI})$ analysed with repeated-measures analysis of variance

${ }^{\mathrm{a}}$ For the whole sample

${ }^{\mathrm{b}}$ Control group is reference

T2DM, type 2 diabetes mellitus 
a

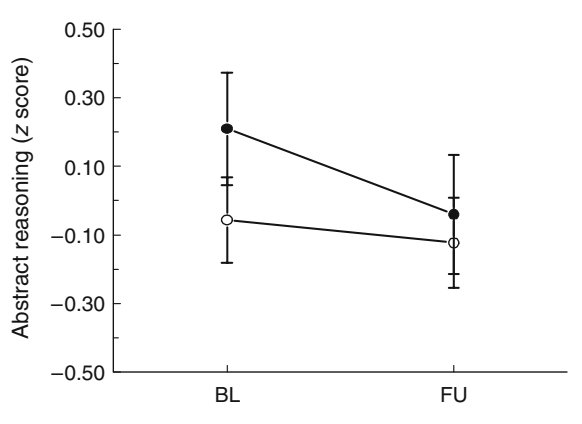

b

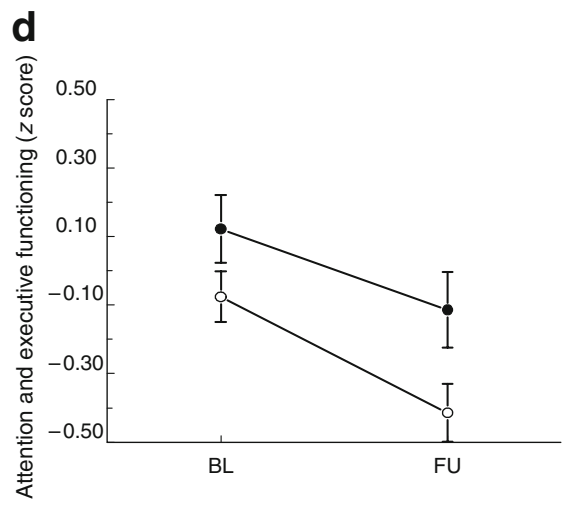

Fig. 1 Cognitive functioning (mean standardised domain score \pm SEM) for the patients with type 2 diabetes (white circles; $n=68$ ) and the control group (black circles; $n=38$ ) at baseline $(\mathrm{BL})$ and 4 year follow-up (FU): a abstract reasoning, main effect of time $p=0.03$, main effect of group $p=0.39$, time $\times$ group interaction $p=0.20$; b memory, main effect of time $p=0.16$, main effect of group $p=0.07$, time $\times$ group interaction $p=0.15$; $\mathbf{c}$ information-processing speed, main

domain only comprised a single test, in contrast to the other domains, may have affected the reliability of this domain score and increased the potential impact of confounding factors such as motivation, ceiling effects or practice effects, particularly for those participants with an initial worse performance.

To date, longitudinal studies that examine the cognitive profile of patients with type 2 diabetes and control participants by means of a detailed neuropsychological test battery are scarce. Two previous case-control studies, with smaller samples of patients with type 2 diabetes than the present study, did not consistently observe accelerated cognitive decline in patients with type 2 diabetes after a 3 to 4 year follow-up [26, 27]. Longitudinal population-based studies, which included less detailed assessment of cognitive functioning than the present study, showed moderate differences in cognitive performance between patients with type 2 diabetes and controls at baseline and follow-up [9, $10,28,29]$, similar to the differences found in the present study. Some of these studies also observe a modest accelerated decline after a 3 to 6 year period on a subset of the cognitive measures $[9,10,29]$ of approximately 1.5 times the decline of the non-diabetic participants. Appar-

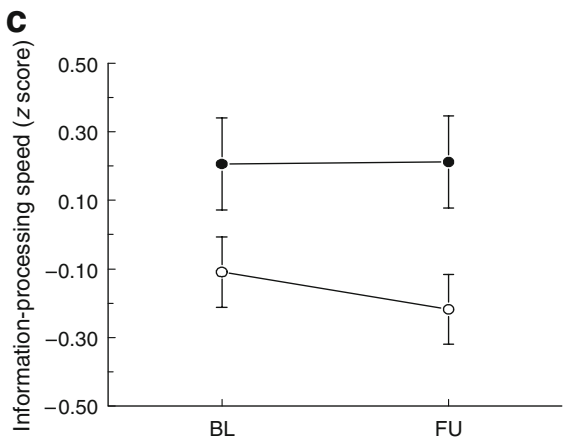

e

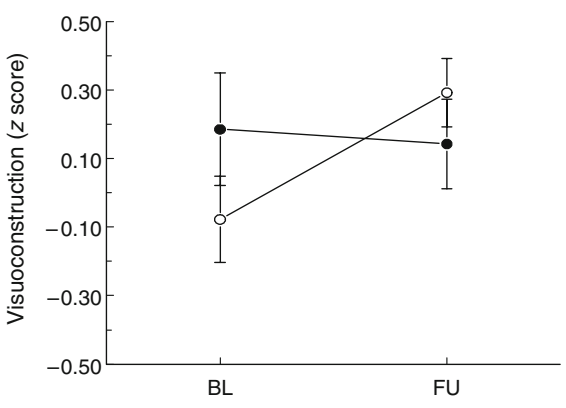

effect of time $p=0.28$, main effect of group $p=0.02$, time $\times$ group interaction $p=0.23$; $\mathbf{d}$ attention and executive functioning, main effect of time $p<0.001$, main effect of group $p=0.04$, time $\times$ group interaction $p=0.37$; e visuoconstruction, main effect of time $p=0.15$, main effect of group $p=0.71$, time $\times$ group interaction $p=0.07 . p$ values indicate the results of the repeated-measures ANOVA

ently, no marked accelerated cognitive decline is found in the majority of patients with type 2 diabetes relative to persons without type 2 diabetes. This is in contrast with prototypic diabetic complications, such as retinopathy, nephropathy and neuropathy, for which prevalence and severity clearly increase with duration of diabetes and exposure to elevated glucose levels. Future aetiological studies should answer the question why cognitive decrements can already be found in prediabetic stages, or at the time of diabetes diagnosis, and progress only slowly thereafter. In prediabetic stages exposure to vascular risk factors such as hypertension, dyslipidaemia and obesity may play a role. Although acute effects of elevated blood glucose levels on cognitive functioning have been reported [30], the present findings suggest that long-term exposure to elevated blood glucose levels apparently do not have a major impact on cognition in patients with type 2 diabetes, a finding in line with recent observations in adult patients with type 1 diabetes [31].

The question also is how these findings relate to the 1.5to twofold increased risk of dementia that is observed in individuals with type 2 diabetes [3]. A likely explanation is that the subtle cognitive decrements that are found in non- 
demented populations do not necessarily evolve into frank cognitive decline in all individuals, but rather that within the population of older patients with type 2 diabetes, severe cognitive decline only occurs in a subgroup of persons, possibly in interaction with other risk factors such as the apolipoprotein E status [32], hypertension [33] or the metabolic syndrome [34]. Furthermore, particularly below the age of 70 years, incident dementia is relatively rare (annual incidence $<1 \%$ per year [35]). This makes dementia a fundamentally different cognitive outcome measure than the more subtle cognitive decrements that are addressed in the present study, which show a normal distribution across the whole study sample.

The present detailed analysis of the neuropsychological profile associated with type 2 diabetes revealed a pattern of modest decrements in information-processing speed and attention and executive functioning, with a non-significant trend in the same direction for memory. This profile appears to reflect an overall diminished performance level rather than deficits in specific cognitive functions [36] and resembles the pattern that is found in normal ageing [36].

The principal strength of the present study is the detailed neuropsychological examination that was performed twice over a 4 year interval in a relatively large sample of patients with type 2 diabetes. Limitations include possible selection bias due to selective attrition during the follow-up period. The results of the TICS-m showed that selection bias due to drop out of persons with severely impaired cognitive functioning was limited. Nevertheless, during follow-up of the non-participants we observed that several persons with marked cognitive decline dropped out of the study, albeit at a low rate that was similar in the two groups. Moreover, the reduction in sample size at the follow-up examination may have limited the power of the statistical analyses, particularly with regard to the time $\times$ group interactions.

In summary, the results of the present study indicate that in functionally independent patients with type 2 diabetes cognitive decrements are modest in size and decline is largely within the range of what can be viewed in normal ageing. Apparently, diabetes-related cognitive changes progress slowly over a prolonged period of time, probably much longer than the 4 years of follow up in the present study.

Acknowledgements This study was supported by grant 2003.01.004 of the Dutch Diabetes Research Foundation. The research of G. J. Biessels and R. P. C. Kessels is supported by a high potential grant from Utrecht University. The Utrecht Diabetic Encephalopathy Study Group consists of (baseline and follow-up study, in alphabetical order): Department of Clinical Neurophysiology: A. C. van Huffelen; Department of Internal Medicine: H. W. de Valk; Julius Center for Health Sciences and Primary Care: A. Algra, G. E. H. M. Rutten; Department of Medical Pharmacology: W. H. Gispen; Department of Neurology: A. Algra, G. J. Biessels, L. J. Kappelle, S. M. Manschot, J. van Gijn; Department of Neuropsychology: Y. Reijmer, E. van den
Berg; Department of Experimental Psychology and Helmholtz Instituut: A. M. A. Brands (currently Zuwe Hofpoort; Regionaal Psychiatrisch Centrum, Woerden, the Netherlands), E. H. F. de Haan (currently University of Amsterdam, Amsterdam, the Netherlands), R. P. C. Kessels (currently Donders Institute for Brain, Cognition and Behaviour; Radboud University Nijmegen Medical Centre, Nijmegen, the Netherlands); Department of Radiology and Image Sciences Institute: J. de Bresser, C. Jongen, W. Mali, A. Tiehuis, J. van der Grond (currently Leiden University Medical Center, Leiden, the Netherlands), M. Viergever, all part of the University Medical Center, Utrecht, the Netherlands. Patients were recruited through the community-based 'Utrecht Diabetes Programma (UDP)' and the 'IJsselstein Diabetes Project' (mentor: Ph. L. Salomé). The UDP is a long-running collaborative project between general practitioners and a hospital-based endocrinologist, with the aim to improve the level of care for patients with type 2 diabetes in the community without referral to the hospital.

Duality of interest The authors declare that there is no duality of interest associated with this manuscript.

Open Access This article is distributed under the terms of the Creative Commons Attribution Noncommercial License which permits any noncommercial use, distribution, and reproduction in any medium, provided the original author(s) and source are credited.

\section{References}

1. Wild S, Roglic G, Green A, Sicree R, King H (2004) Global prevalence of diabetes: estimates for the year 2000 and projections for 2030. Diabetes Care 27:1047-1053

2. Ferri CP, Prince M, Brayne C et al (2005) Global prevalence of dementia: a Delphi consensus study. Lancet 366:2112-2117

3. Biessels GJ, Staekenborg S, Brunner E, Brayne C, Scheltens P (2006) Risk of dementia in diabetes mellitus: a systematic review. Lancet Neurol 5:64-74

4. Ryan CM, Geckle MO (2000) Circumscribed cognitive dysfunction in middle-aged adults with type 2 diabetes. Diabetes Care 23:1486-1493

5. Dey J, Misra A, Desai NG, Mahapatra AK, Padma MV (1997) Cognitive function in younger type II diabetes. Diabetes Care 20:32-35

6. Awad N, Gagnon M, Messier C (2004) The relationship between impaired glucose tolerance, type 2 diabetes, and cognitive function. J Clin Exp Neuropsychol 26:1044-1080

7. Stewart R, Liolitsa D (1999) Type 2 diabetes mellitus, cognitive impairment and dementia. Diabet Med 16:93-112

8. Brands AM, van den Berg E, Manschot SM et al (2007) A detailed profile of cognitive dysfunction and its relation to psychological distress in patients with type 2 diabetes mellitus. J Int Neuropsychol Soc 13:288-297

9. Gregg EW, Mangione CM, Cauley JA et al (2002) Diabetes and incidence of functional disability in older women. Diabetes Care 25:61-67

10. Kanaya AM, Barrett-Connor E, Gildengorin G, Yaffe K (2004) Change in cognitive function by glucose tolerance status in older adults: a 4-year prospective study of the Rancho Bernardo study cohort. Arch Intern Med 164:1327-1333

11. Manschot SM, Brands AM, van der Grond J et al (2006) Brain magnetic resonance imaging correlates of impaired cognition in patients with type 2 diabetes. Diabetes 55:1106-1113

12. Kempen GI, Meier AJ, Bouwens SF, van Deursen J, Verhey FR (2007) The psychometric properties of the Dutch version of the 
Telephone Interview Cognitive Status (TICS). Tijdschr Gerontol Geriatr 38:38-45

13. Brandt J, Spencer M, Folstein M (1988) The telephone interview for cognitive status. Neuropsychiatry Neuropsychol Behav Neurol 2:111-117

14. Welsh KA, Breitner JCS, Magruder-Habib KM (1993) Detection of dementia in the elderly using telephone screening of cognitive status. Neuropsychiatry Neuropsychol Behav Neurol 6:103-110

15. Crooks VC, Clark L, Petitti DB, Chui H, Chiu V (2005) Validation of multi-stage telephone-based identification of cognitive impairment and dementia. BMC Neurol 5:8

16. Lezak MD, Howieson DB, Loring DW (2004) Neuropsychological assessment, 4th edn. Oxford University Press, New York

17. Kessels RP, van Zandvoort MJ, Postma A, Kappelle LJ, de Haan EH (2000) The Corsi Block-Tapping Task: standardization and normative data. Appl Neuropsychol 7:252-258

18. Beck AT, Steer RA, Brown GK (1996) Manual for Beck Depression Inventory II (BDI-II). Psychology Corporation, San Antonio

19. Lustman PJ, Clouse RE, Griffith LS, Carney RM, Freedland KE (1997) Screening for depression in diabetes using the Beck Depression Inventory. Psychosom Med 59:24-31

20. Klein R, Klein BE, Magli YL et al (1986) An alternative method of grading diabetic retinopathy. Ophthalmology 93:1183-1187

21. Bril V, Perkins BA (2002) Validation of the Toronto Clinical Scoring System for diabetic polyneuropathy. Diabetes Care 25:2048-2052

22. Manschot SM, Biessels GJ, de Valk H et al (2007) Metabolic and vascular determinants of impaired cognitive performance and abnormalities on brain magnetic resonance imaging in patients with type 2 diabetes. Diabetologia 50:2388-2397

23. van Harten B, Oosterman J, Muslimovic D, van Loon BJ, Scheltens P, Weinstein HC (2007) Cognitive impairment and MRI correlates in the elderly patients with type 2 diabetes mellitus. Age Ageing 36:164-170

24. Vanhanen M, Koivisto K, Kuusisto J et al (1998) Cognitive function in an elderly population with persistent impaired glucose tolerance. Diabetes Care 21:398-402
25. Ruis C, Biessels GJ, Gorter KJ, van den Donk M, Kappelle LJ, Rutten GE (2009) Cognition in the early stage of type 2 diabetes mellitus. Diabetes Care 32:1261-1265

26. Fischer AL, de Frias CM, Yeung SE, Dixon RA (2009) Short-term longitudinal trends in cognitive performance in older adults with type 2 diabetes. J Clin Exp Neuropsychol 31:809-822

27. Aberle I, Kliegel M, Zimprich D (2009) Cognitive development in young-old type 2 diabetes patients: a longitudinal analysis from the 'Interdisciplinary Longitudinal Study of Aging'. Curr Psychol 27:6-15

28. Kumari M, Marmot M (2005) Diabetes and cognitive function in a middle-aged cohort: findings from the Whitehall II study. Neurology 65:1597-1603

29. Fontbonne A, Berr C, Ducimetiere P, Alperovitch A (2001) Changes in cognitive abilities over a 4-year period are unfavorably affected in elderly diabetic subjects: results of the Epidemiology of Vascular Aging Study. Diabetes Care 24:366-370

30. Cox DJ, Kovatchev BP, Gonder-Frederick LA et al (2005) Relationships between hyperglycemia and cognitive performance among adults with type 1 and type 2 diabetes. Diabetes Care 28:71-77

31. Jacobson AM, Musen G, Ryan CM et al (2007) Long-term effect of diabetes and its treatment on cognitive function. N Engl J Med 356:1842-1852

32. Peila R, Rodriguez BL, Launer LJ (2002) Type 2 diabetes, APOE gene, and the risk for dementia and related pathologies: The Honolulu-Asia Aging Study. Diabetes 51:1256-1262

33. Luchsinger JA, Reitz C, Honig LS, Tang MX, Shea S, Mayeux R (2005) Aggregation of vascular risk factors and risk of incident Alzheimer disease. Neurology 65:545-551

34. Sandbaek A, Griffin SJ, Rutten G et al (2008) Stepwise screening for diabetes identifies people with high but modifiable coronary heart disease risk. The ADDITION study. Diabetologia 51:1127-1134

35. Launer LJ, Andersen K, Dewey ME et al (1999) Rates and risk factors for dementia and Alzheimer's disease: results from EURODEM pooled analyses. EURODEM Incidence Research Group and Work Groups. European Studies of Dementia. Neurology 52:78-84

36. Tisserand DJ, Jolles J (2003) On the involvement of prefrontal networks in cognitive ageing. Cortex 39:1107-1128 